\title{
The employment of Fourier Transform Infrared Spectroscopy (FTIR) and chemometrics for analysis of candlenut oil in binary mixture with grape seed oil
}

\author{
${ }^{1,2}$ Riyanta, A.B., ${ }^{1}$ Riyanto, S., ${ }^{1}$ Lukitaningsih, E. and ${ }^{1,3}$ Rohman, A. \\ ${ }^{1}$ Department of Pharmaceutical Chemistry, Faculty of Pharmacy, Universitas Gadjah Mada, Yogyakarta \\ ${ }^{2}$ Department of Pharmacy, Politeknik Harapan Bersama, Central Java 52147 Indonesia \\ ${ }^{3}$ Institute of Halal Industry and Systems, Universitas Gadjah Mada, Yogyakarta 55281 Indonesia
}

\begin{abstract}
Article history:
Received: 5 August 2019

Received in revised form: 5

September 2019

Accepted: 8 September 2019

Available Online: 11

September 2019
\end{abstract}

\section{Keywords:}

Candlenut oil,

Grapeseed oil,

Multivariate calibration,

Partial least square

regression,

Discriminant analysis

DOI:

https://doi.org/10.26656/fr.2017.4(1).279

\begin{abstract}
Candlenut oil (CDO) is the target of adulteration with other plant oils to get economical profits, therefore, reliable analytical techniques should be developed. Based on the principal component analysis (PCA), grape seed oil (GSO) has the close similarity with CDO. Therefore, this study was intended to make modelling in the authentication analysis of CDO from GSO using Fourier transformed infrared (FTIR) spectroscopy in combination with chemometrics of partial least square calibration (PLSR) and discriminant analysis (DA). FTIR spectra of CDO, GSO and its binary mixtures were subjected to FTIR spectral measurement at wavenumbers of $4000-650 \mathrm{~cm}^{-1}$, and its absorbances were used for modelling of PLSR and DA. FTIR spectra were also subjected to pre-processing including Savitzy-Golay derivatization. The optimization results showed that FTIR spectra using second derivative at the combined wavenumbers of 3000-2800 and $1600-650 \mathrm{~cm}^{-1}$ offered the optimum models. The coefficient determination $\left(\mathrm{R}^{2}\right)$ for the relationship between actual values and FTIR predicted values was 0.9996 and 0.9975 in calibration and internal validation (prediction) models, respectively. The errors in calibration and validation were relatively low, i.e. $0.84 \%$ and $2.19 \% \mathrm{vol} / \mathrm{vol}$, respectively. Using the same FTIR spectra, DA could discriminate pure CDO and that mixed with GSO at concentration range of $1-50 \% \mathrm{vol} / \mathrm{vol}$. The combination of FTIR spectroscopy and chemometrics offered effective tools for the quantification and discrimination of CDO mixed with GSO with the main advantage of its simplicity and rapidity.
\end{abstract}

\section{Introduction}

Candlenut with the scientific name of Aleurites moluccana L., belonging to family of Euphorbiaceae is known with several names including kemiri in Indonesia, Kukui nut in Hawaii, and buah keras in Malaysia. This plant is flowering tree, typically having height up to $20 \mathrm{~m}$ (Norulaini et al., 2004; Krisnawati et al., 2011). The plant of $A$. moluccana is originating from the IndoMalaysia region and the productivity of the oil yield obtained from its seed is approximately $3200 \mathrm{~kg} / \mathrm{ha}$ annually. The leave's decoction of A. moluccana has been reported in folk medicines to treat diarrhea, coughs, headaches, hernia, ulcers, fever, and gonorrhoea (Quintãoa et al., 2019), while candlenut oil has been applied topically to treat arthritis and other joint pain (Judd, 1998). Unfortunately, the seeds of plant are considered toxic for oral use (González-Stuart and Rivera, 2003). Candlenut oil (CDO), widely sold in cosmetics industry, has been used as good material for soap, varnish, and other oil-based cosmetics products.
Furthermore, the remaining seed cake after oil extraction can be exploited as fertilizer or animal fodder (Elevitch and Manner, 2006; Subroto et al., 2017).

Due to its good properties to be used in pharmaceutical and cosmetics products, CDO has an expensive price in the oil industries and maybe target to be adulterated with other plant oils having lower price to get economical profit (Yuliani et al., 2018). The authentication of high price oils such as CDO is interesting issue in fats and oils industry not only for economic reasons but also for health safety concerns (Abbas et al., 2018). The vegetable oil authentication has been regarded as nice area of research and requires reliable analytical techniques to perform. The authentication analysis is usually carried out by fingerprinting profiling between authentic oil and adulterated oils. In addition, some authors used the major components such as triacylglycerol composition and fatty acid profiles as well as minor components such as tocopherols, carotenes, sterols, and volatile organic 
compounds to detect the oil adulteration (Milanez et al., 2017).

Numerous analytical methods have been employed for authentication purposes based on molecular biology and physico-chemical properties such as chromatographic based techniques through analysis of major components of fatty acids and triacylglycerol compositions (Blasi et al., 2019) and minor components like tocopherol contents (Cserhati et al., 2005; BosqueSendra et al., 2012), visible spectroscopy (FerreiroGonzález et al., 2011), synchronous fluorescence by analyzing the specific components capable of exhibiting photo-luminescence (Poulli et al., 2007; Ge et al., 2014), Ultrafast 2D nuclear magnetic spectroscopy (NMR) in combination with principal component analysis (Gouilleux et al., 2018), ambient mass spectrometry using direct analysis in real-time (Vaclavik et al., 2009) and vibrational-based spectroscopy such as infrared and Raman spectroscopy by applying specific wavenumbers corresponding wavenumbers specific to analyte(s) of interest (El-Abassy et al., 2009; Rohman and Che Man, 2012). Among these techniques, Fourier transformed infrared spectroscopy (FTIR) spectroscopy is the most commonly used techniques for authentication of edible oils.

Combined with multivariate regression of partial least square and classification of principal component analysis (PCA) and discriminant analysis (DA), FTIR spectroscopy has emerged a powerful means for authentication of high price edible oils such as detection of hazelnut oil as adulterant in olive oil (Beaten et al., 2005), authentication analysis of walnut oil from soybean oil (Li et al., 2015), detection and quantification of soybean oil in binary mixture with cold-pressed black cumin seed oil (Arslan et al., 2019), and ternary mixture with black cumin seed oil and corn oil (Rohman and Ariani, 2013). Using literature review, only one publication reporting the authentication of candlenut oil (CDO) from palm oil and corn oil. CDO has similar color with GSO which make the authentication analysis using color difference is rather difficult so that the use of instrumental analysis such as FTIR spectrophotometer is highly needed. This study applied FTIR spectroscopy coupled with chemometrics for authentication of CDO from grape seed oil having close FTIR spectra based on score plot principal component analysis.

\section{Materials and methods}

\subsection{Materials}

A total of twenty nine edible and non-edible oils namely cumin oil, rice bran oil, sunflower seed oil, coconut oil, pumpkin seed oil, sesame oil, candlenut oil,
Dayak onion oil, soybean oil, extra virgin olive oil, olive oil, grape seed oil, canola oil, castor oil, palm oil, corn oil, garlic oil, cananga oil, rose oil, orange oil, fannel oil, clove oil, eucalyptus oil, peppermint oil, paraffin liquid and aring oil were obtained from different markets around Yogyakarta. The other solvents and reagents were of pro-analytical grade.

\subsection{Preparation of candlenut oil}

Candlenut oil was prepared by direct pressing of candlenut seed using designed apparatus in Figure 1. The seed of candlenut was placed on the top of apparatus and the temperature was set at $80^{\circ} \mathrm{C}$. The apparatus works as follows: when the temperature has reached $80^{\circ} \mathrm{C}$, the seed of candlenut was pressed until the oil is separated from the pulp. Candlenut oil (CDO) obtained exhibited light yellow oil in color. CDO obtained was further used for the authentication studies using FTIR spectroscopy.

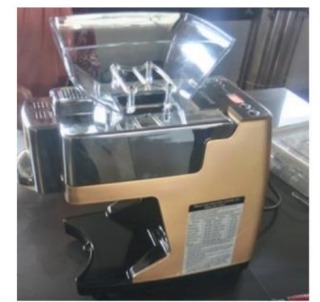

[A]

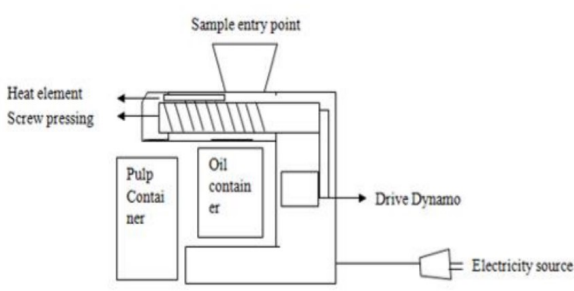

[B]
Figure 1. Apparatus used for pressing seed of candlenut to obtain candlenut oil.

\subsection{Principal component analysis}

Principal component analysis (PCA) was used for searching the oil having close similarity with $\mathrm{CDO}$ to make adulteration model. A total of twenty-nine samples of edible and non-edible oils were analyzed using PCA. As independent variables, absorbances at several wavenumbers were used and the responses investigated were score plot at first principle component (PC1) and second principle component (PC2). The closer PC1 and PC2 value, the more similar of oils based on used variables. PCA was carried out using Minitab software version 17 (Minitab Inc., USA).

\subsection{Preparation of calibration and validation samples}

Based on PCA results, grape seed oil (GSO) has the close $\mathrm{PC} 1$ and $\mathrm{PC} 2$ values with $\mathrm{CDO}$, therefore GSO was used as oil model for adulteration analysis. For making calibration samples, twenty-six samples with a concentration range of $\mathrm{CDO}$ and GSO $0-100 \%$ were prepared by mixing both oils using calibrated pipette. For validation samples, a set of independent samples was also prepared. All samples were scanned using FTIR spectrophotometer. 


\subsection{Discriminant analysis}

Discriminant analysis (DA) is one of the supervised pattern recognitions. During preparing of DA models, pure $\mathrm{CDO}$ and $\mathrm{CDO}$ mixed with GSO at the level range of $0.5-50.0 \%$ (volume/volume) was prepared. Pure PSO was marked as pure. In addition, CDO mixed with GSO was marked as adulterated. Both classes (pure CDO and adulterated samples) were subjected to DA using variables of Mahalanobis distance based on absorbance values at optimized wavenumbers region.

\subsection{FTIR spectra acquisition}

The FTIR spectra of all studied samples were scanned using FTIR spectrophotometer (Thermo Scientific Nicolet iS10, Madison, WI), controlled with the operating software of Omnic ${ }^{\circledR}$. The measurements were performed in mid-infrared region of $4000-650 \mathrm{~cm}^{-1}$ with 32 scanning and the resolution was $8 \mathrm{~cm}^{-1}$ using horizontal attenuated total reflectance (HATR) composed of ZnSe crystal. All FTIR spectra were corrected against FTIR spectrum of air as background. After every scan, a new reference air background spectrum was taken. These spectra were recorded as absorbance values at each data point in triplicate.

\subsection{Statistical analysis}

Chemometrics analysis of PCA was carried out using Minitab version 17.0 software (Minitab Inc., USA). The multivariate calibration of partial least square regression (PLSR) and discriminant analysis (DA) was performed using TQ Analyst software version 9 (Thermo Fisher Scientific, Inc.). PLSR is one of inversed multivariate calibration in which concentration of analytes (y-axis) was modelled with absorbance values ( $\mathrm{x}$-axis) at certain wavenumbers.

\section{Results and discussion}

The first step for authentication study of candlenut oil (CDO) with other oils, principal component analysis (PCA) was applied to search oils having close similarity with $\mathrm{CDO}$ based on absorbance values at whole midinfrared region $\left(4000-650 \mathrm{~cm}^{-1}\right)$. PCA is one of the unsupervised pattern recognition techniques commonly applied to classify the samples. Figure 2 shows PCA score plot of $\mathrm{CDO}$ and other oils in which $\mathrm{CDO}$ has close similarity with grape seed oil (GSO), therefore GSO was selected as model of oil adulterant. CDO and GSO also has the close similarity in fatty acid compositions in which Stearic (C18:0), oleic acid (C18:1) and linoleic (C18:2) acids were dominated fatty acids in both CDO and GSO (Che Man et al., 2011; Yuliani et al., 2018).

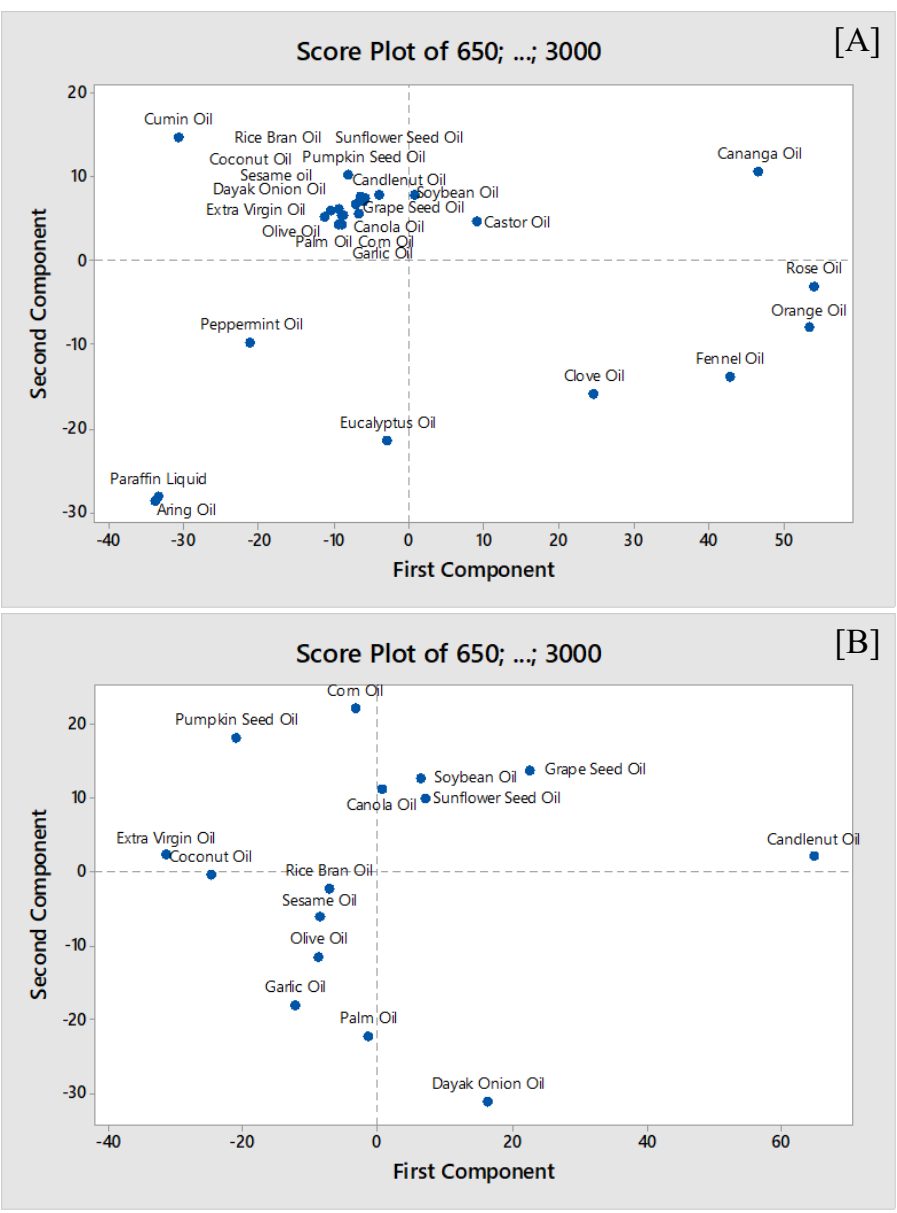

Figure 2. The score plot of principal component analysis (PCA) expressed by first principle component (PC1) and second principle component (PC2) for classification of 29 edible and non-edible samples [A] and 16 edible samples [B].

Figure 3 reveals the peaks and shoulders of FTIR spectra of CDO and GSO obtained at mid-infrared region (4000-650 $\mathrm{cm}^{-1}$ ) representing the functional groups responsible for infrared absorption. The absorption of functional groups in each wavenumber fit the LambertBeer law, in which the intensity of each peak related with concentration, thus FTIR spectra could be effective means for authentication studies of edible fats and oils. Table 1 compiles the wavenumbers of each peak and shoulders in FTIR spectra of CDO and GSO and the corresponding functional groups' vibration (Rohman and Ariani, 2013). The functional groups composed CDO and GSO are basically similar to those in triacylglycerols (TAG), because fats and oils are basically composed of TAG (approximately 98\%). Both spectra look very similar, but using detailed investigation there is a bit different in peak intensities at around $3000 \mathrm{~cm}^{-1}$ and at fingerprint regions $\left(1500-650 \mathrm{~cm}^{-1}\right)$. Therefore, this difference could be target of optimization of FTIR spectra in terms of selection of wavenumbers region and spectral treatment (normal versus derivatization).

Partial least square calibration (PLSR) and principle component regression (PCR) were selected for prediction of CDO adulterated with GSO. PLS and PCR are inverse 


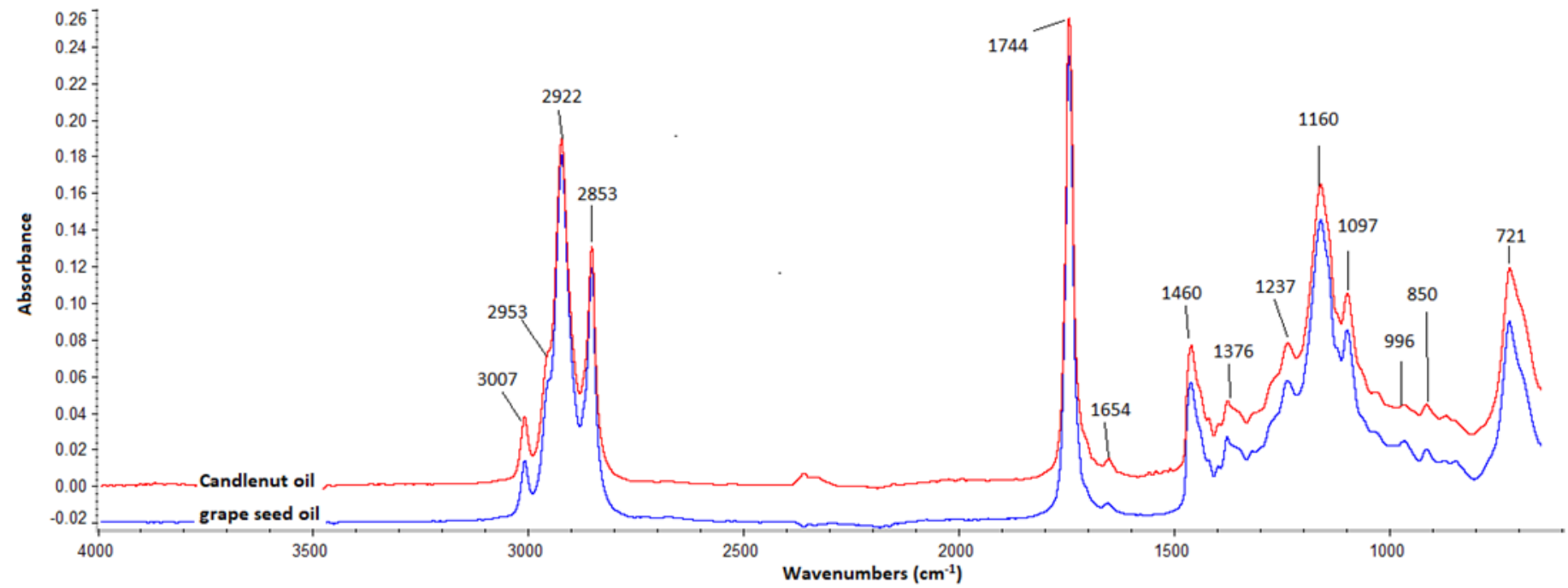

Figure 3. FTIR spectra of candlenut oil and grape seed oil scanned in mid infrared region corresponding to wavenumbers of $4000-650 \mathrm{~cm}^{-1}$.

Table 1. The wavenumbers of FTIR spectra of candlenut oil and grape seed oil and the corresponding functional groups' vibration (Rohman and Ariani, 2013)

\begin{tabular}{clcl}
\hline Wavenumber $\left(\mathrm{cm}^{1}\right)$ & Type of bending and vibration & Wavenumber $\left(\mathrm{cm}^{-1}\right)$ & Type of bending and vibration \\
\hline 3009 & $\mathrm{C}=\mathrm{CH}$ Stretching & 1235 and 1161 & $\mathrm{C}-\mathrm{O}$ (ester) Stretching \\
2922 dan 2852 & $-\mathrm{CH}\left(\mathrm{CH}_{3}\right)$ Stretching Asymmetric & 1118 dan 1098 & C-O Stretching \\
1742 & $-\mathrm{C}=\mathrm{O}$ (ester) Stretching & 964 & trans- $\mathrm{CH}=\mathrm{CH}-$ Bending out of plane \\
1658 & $-\mathrm{C}=\mathrm{C}($ cis $)$ Stretching & 914 & trans- $\mathrm{CH}=\mathrm{CH}-\mathrm{Bending}$ out of plane \\
1461 & $-\mathrm{C}-\mathrm{H}\left(\mathrm{CH}_{2}\right)$ Bending (scissoring) & 871 & trans- $\mathrm{CH}=\mathrm{CH}-\mathrm{Bending}$ out of plane \\
1378 & $-\mathrm{C}-\mathrm{H}\left(\mathrm{CH}_{3}\right)$ Bending symmetric & 844 & trans- $\mathrm{CH}=\mathrm{CH}-\mathrm{Bending}$ out of plane \\
\hline
\end{tabular}

regression in which absorbance values were used as independent variables. The absorbance values were combined to get new variables are known as principle components (in PCR) or PLS factors. Then, these factors were used for modelling the concentration of analytes. PLSR provide better predictive power over PCR (data are not shown), therefore, PLSR was then used for next optimization process. Table 2 compiles the performance of PLSR for quantitative analysis of CDO in binary mixture with GSO in calibration and validation models using different wavenumber regions and FTIR spectral treatment. The condition selected was relied on the capability to give the highest coefficient of determination $\left(\mathrm{R}^{2}\right)$ for the relationship between actual values of CDO and predictive values and the errors, expressed by root mean square error of calibration (RMSEC) and root mean square error of prediction (RMSEP), in calibration and validation models. The $\mathrm{R}^{2}$ value could be used as predictive the accuracy of developed model. The higher $\mathrm{R}^{2}$, the more accurate of the models. In addition, RMSEC and RMSEP described the difference between actual and predicted values using the selected model, therefore RMSEC and RMSEP expressed the precision of model. The lower RMSEC and RMSEP values, the more precise of the developed model. Based on the highest $\mathrm{R}^{2}$ and the lowest errors, the second derivative FTIR spectra at the combined wavenumber of 3000-2800 and $1600-650 \mathrm{~cm}^{-1}$ offered the best models. The $\mathrm{R}^{2}$ values were 0.9996 and 0.9975 in calibration and internal validation (prediction) models, respectively. This can be also stated that the accuracy of calibration and validation models was $99.96 \%$ and $99.75 \%$, respectively. The errors in calibration and validation were relatively low, i.e. $0.84 \%$ and $2.19 \% \mathrm{vol} / \mathrm{vol}$, respectively (Figure $4[\mathrm{~A}]$ ). The residual analysis confirmed that error occurred above and below the zero difference (as in Figure 4[B]), therefore the error occurring is random error, not systematic error.

In order to discriminate between $\mathrm{CDO}$ and $\mathrm{CDO}$ adulterated with GSO, discriminant analysis (DA) based on Mahalanobis distance was used. Using the same FTIR spectra (the second derivative FTIR spectra at the combined wavenumber of 3000-2800 and $1600-650 \mathrm{~cm}^{-}$ ${ }^{1}$ ), DA could discriminate pure CDO and that mixed with GSO at a concentration range of $1-50 \% \mathrm{vol} / \mathrm{vol}$ without any misclassification reported (Figure 5).

\section{Conclusion}

The combination of chemometrics of PLSR and discriminant analysis-second derivative FTIR spectra at combined wavenumber regions of 3000-2800 and 1600$650 \mathrm{~cm}^{-1}$ resulted in the effective analytical techniques for the quantification and discrimination of CDO mixed 
Table 2. The performance of partial least square regression for quantitative analysis of candlenut oil in binary mixture with grape seed oil in calibration and validation models.

\begin{tabular}{clccccc}
\hline \multirow{2}{*}{ Wavenumber $\left(\mathrm{cm}^{-1}\right)$} & \multirow{2}{*}{ Spectra } & \multirow{2}{*}{ Factor } & \multicolumn{2}{c}{ Calibration } & \multicolumn{2}{c}{ Validation } \\
\cline { 3 - 6 } & & & RMSEC & $\mathrm{R}^{2}$ & RMSEP & $\mathrm{R}^{2}$ \\
\hline \multirow{3}{*}{$4000-650$} & Normal & 7 & 0.45 & 0.9999 & 2.21 & 0.9978 \\
& Derivate 1 & 3 & 0.7 & 0.9997 & 2.36 & 0.9975 \\
& Derivate 2 & 2 & 1.34 & 0.999 & 2.92 & 0.9961 \\
& Normal & 5 & 1.21 & 0.9992 & 2.17 & 0.9978 \\
$3000-2800$ and 1600-650 & Derivate 1 & 3 & 1.44 & 0.9988 & 2.48 & 0.9971 \\
& Derivate 2 & 4 & $\mathbf{0 . 8 4}$ & $\mathbf{0 . 9 9 9 6}$ & $\mathbf{2 . 1 9}$ & $\mathbf{0 . 9 9 7 5}$ \\
& Normal & 4 & 2.61 & 0.9962 & 2.97 & 0.9955 \\
$3050-2800$ & Derivate1 & 3 & 2.43 & 0.9967 & 2.66 & 0,9969 \\
& Derivate 2 & 3 & 2.71 & 0.9959 & 3.15 & 0.9955 \\
& Normal & 3 & 2.26 & 0.9972 & 3.2 & 0.996 \\
& Derivate 1 & 3 & 1.84 & 0.9981 & 3.04 & 0.9958 \\
& Derivate 2 & 3 & 1.8 & 0.9982 & 2.86 & 0.9962 \\
\hline
\end{tabular}

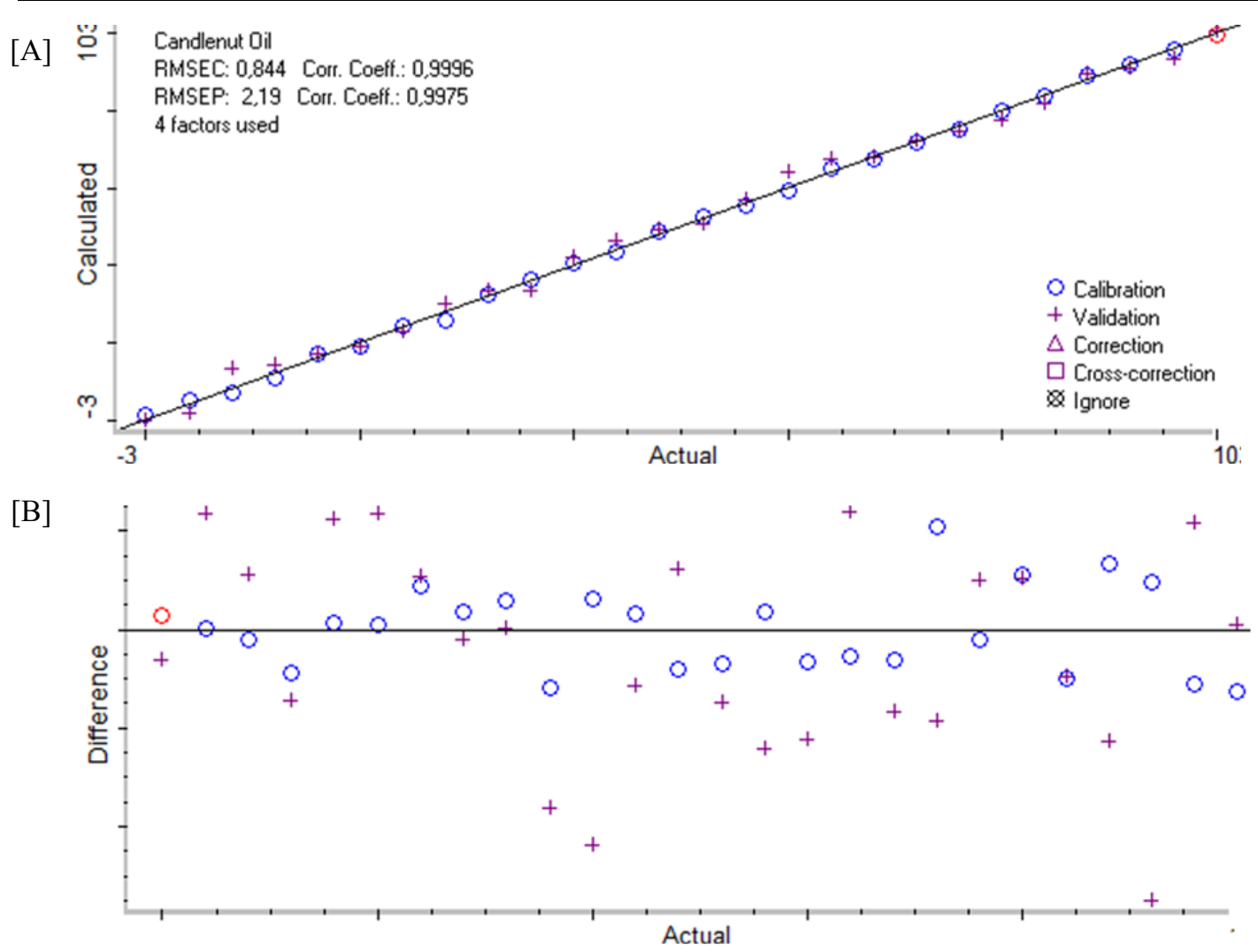

Figure 4. The relationship between actual values of candlenut oil in \%volume/volume ( $\mathrm{x}$-axis) and FTIR predicted values in calibration and validation models [A] along with residual analysis [B].

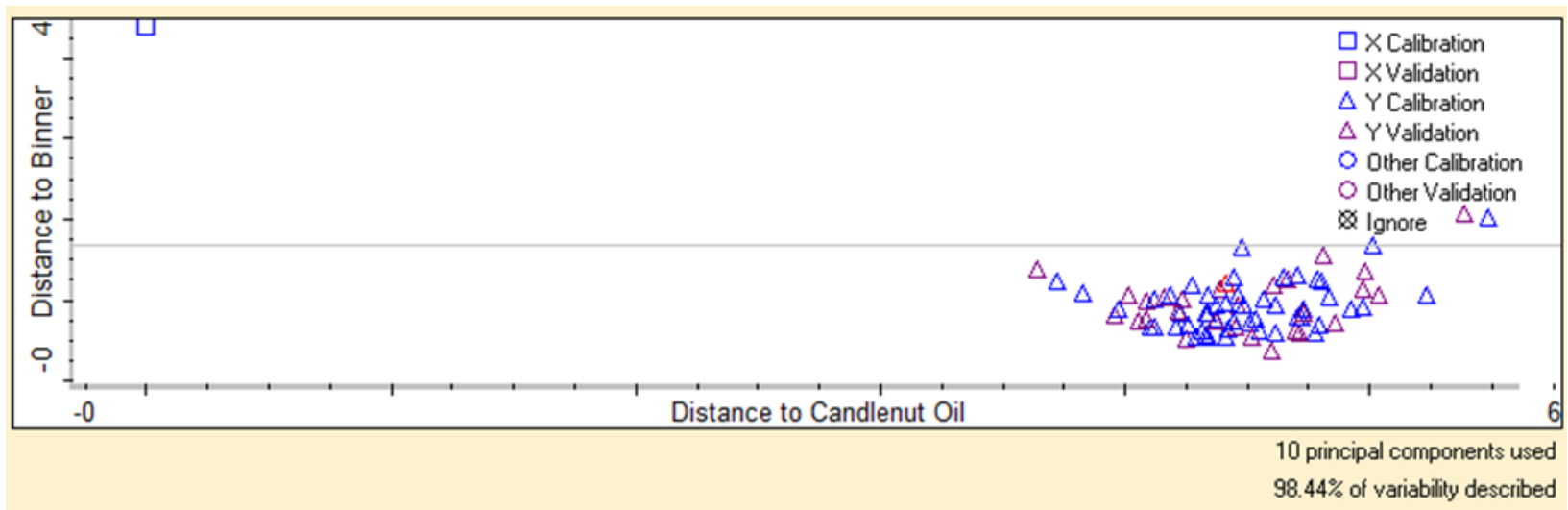

Figure 5. The Cooman's plot obtained during discriminant analysis for discrimination of pure candlenut oil and candlenut oil mixed with grape seed oil. 
with GSO with acceptable accuracy as indicated by high $\mathrm{R}^{2}$ values and acceptable precision with low RMSEC and RMSEP values. The developed method offered the main advantage of its simplicity and rapidity. Besides, FTIR spectra also promising analytical method for rapid screening of adulteration practice due to its nature as fingerprint analytical method.

\section{Acknowledgement}

The authors thank to Universitas Gadjah Mada, Yogyakarta Indonesia for financial support during this research via the scheme Rekognisi Tugas Akhir year 2019 awarded to Prof. Dr. Abdul Rohman with contract number of 2129/UN1/DITLIT/DIT-LIT/LT/2019.

\section{References}

Abbas, O., Zadravec, M., Baeten, V., Mikuš, T., Lešić, T., Vulić, A., Prpic, J., Jemersic, L. and Pleadin, J. (2018). Analytical methods used for the authentication of food of animal origin. Food Chemistry, 246, 6-17. https://doi.org/10.1016/ j.foodchem.2017.11.007

Arslan, F.N., Akin, G., Elmas, S.N.K., Yilmaz, I., Janssen, H.G. and Kenar, A. (2019). Rapid detection of authenticity and adulteration of cold pressed black cumin seed oil: A comparative study of ATR-FTIR spectroscopy and synchronous fluorescence with multivariate data analysis. Food Control, 98, 323332. https://doi.org/10.1016/j.foodcont.2018.11.055

Beaten, V., Pierna, J.A., Dardenne, P., Meurens, M., García-González, D.L. and Aparicio-Ruiz, R. (2005). Detection of the presence of hazelnut oil in olive oil by FT-Raman and FT-MIR spectroscopy. Journal of Agriculture and Food Chemistry, 53, 6201-6206. https://doi.org/10.1021/jf050595n

Blasi, F., Pollini, L. and Cossignani, L. (2019). Varietal Authentication of Extra Virgin Olive Oils by Triacylglycerols and Volatiles Analysis. Foods, 8(2), 58. https://doi.org/10.3390/foods 8020058

Bosque-Sendra, J.M., Cuadros-Rodríguez, L., RuizSamblás, C. and de la Mata, A.P. (2012). Combining chromatography and chemometrics for the characterization and authentication of fats and oils from triacylglycerol compositional data-A review. Analytica Chimica Acta, 724, 1-11. https:// doi.org/10.1016/j.aca.2012.02.041

Che Man, Y.B., Rohman, A. and Mansor, T.S.T. (2011). Differentiation of Lard from Other Edible Fats and Oils by Means of Fourier Transform Infrared Spectroscopy and Chemometrics. Journal of the American Oil Chemists' Society, 88(2), 187-192. https://doi.org/10.1007/s11746-010-1659-x
Cserhati, T., Forgacs, E., Deyl, Z. and Miksik, I. (2005). Chromatography in authenticity and traceability tests of vegetable oils and dairy products: a review. Biomedical Chromatography, 19(3), 183-190. https://doi.org/10.1002/bmc.486

El-Abassy, R.M., Donfack, P. and Materny, A. (2009). Visible Raman spectroscopy for the discrimination of olive oils from different vegetable oils and the detection of adulteration. Journal of Raman Spectroscopy, 40(9), 1284-1289. https:// doi.org/10.1002/jrs.2279

Elevitch, C.R. and Manner, H.I. (2006). Traditional tree initiative: species profiles for Pacific islands agroforestry-ecological, economic, and cultural renewal. Retrieved on June 12, 2019 from Agroforestry website: http://www.agroforestry.net/ $\mathrm{tti} /$ Aleurites-kukui.pdf.

Ferreiro-González, M., Barbero, G.F., Álvarez, J.A., Ruiz, A., Palma, M. and Ayuso, J. (2017). Authentication of virgin olive oil by a novel curve resolution approach combined with visible spectroscopy. Food Chemistry, 220, 331-336. https://doi.org/10.1016/j.foodchem.2016.10.015

Ge, F., Chen, C., Liu, D. and Zhao, S. (2014). Rapid quantitative determination of walnut oil adulteration with sunflower oil using fluorescence spectroscopy. Food Analytical Methods, 7(1), 146-150. https:// doi.org/10.1007/s12161-013-9610-Z

Gouilleux, B., Marchand, J., Charrier, B., Remaud, G.S. and Giraudeau, P. (2018). High-throughput authentication of edible oils with benchtop ultrafast 2D NMR. Food Chemistry, 244, 153-158. https:// doi.org/10.1016/j.foodchem.2017.10.016

González-Stuart, A.E. and Rivera, J.O. (2003). Toxicity of candlenut seed (Aleurites moluccanus), a purported herbal weight loss supplement. Advanced Drug Delivery Reviews, 55, 935-948.

Judd, N. (1998). Herbal healing among contemporary Hawaiian healers. Pacific Health Dialog, 5, 239245.

Krisnawati, H., Kallio, M. and Kanninen, M. (2011). Aleurites moluccana (L.) Wild: Ecology, silviculture and productivity. Bogor: Center for International Forestry Research.

Li, B., Wang, H., Zhao, Q., Ouyang, J. and Wu, Y. (2015). Rapid detection of authenticity and adulteration of walnut oil by FTIR and fluorescence spectroscopy: A comparative study. Food Chemistry, 181, 25-30. https://doi.org/10.1016/ j.foodchem.2015.02.079

Milanez, K.D.T.M., Nóbrega, T.C.A., Nascimento, D.S., Insausti, M., Band, B.S.F. and Pontes, M.J.C. 
(2017). Multivariate modeling for detecting adulteration of extra virgin olive oil with soybean oil using fluorescence and UV-Vis spectroscopies: A preliminary approach. Lebensmittel-Wissenschaft und -Technologie- Food Science and Technology, 85 (Part A), 9-15. https://doi.org/10.1016/ j.lwt.2017.06.060

Norulaini, N.N.A., Budi, R.S., Omar, A. and Zaidul, M.L.S. (2004). Major chemical constituents of candlenut oil extract using supercritical carbon dioxide. Malaysian Journal of Pharmaceutical Sciences, 2(1), 61-72.

Poulli, K.I., Mousdis, G.A. and Georgiou, C.A. (2007). Rapid synchronous fluorescence method for virgin olive oil adulteration assessment. Food Chemistry, 105(1), 369-375. https://doi.org/10.1016/ j.foodchem.2006.12.021

Rohman, A. and Che Man, Y.B. (2012). Application of Fourier transforms infrared spectroscopy for authentication of functional food oils. Applied Spectroscopy Reviews, 47(1), 1-13. https:// doi.org/10.1080/05704928.2011.619020

Rohman, A. and Ariani, R. (2013). Authentication of Nigella sativa Seed Oil in Binary and Ternary Mixtures with Corn Oil and Soybean Oil Using FTIR Spectroscopy Coupled with Partial Least Square. The Scientific World Journal: Analytical Chemistry, 2013, 1-6. https:// doi.org/10.1155/2013/740142

Quintãoa, N.M., Pastor, M.V.D., de-Souza Antonialli, C., da Silva, G.F., Rocha, L.W., Berté, T.E., Souza, M.M.D., Meyre-Silva, C., Lucinda-Silva, R.M., Bresolin, T.M.B. and Filho, V.C. (2019). Aleurites moluccanus and its main active constituent, the flavonoid 2"-Orhamnosylswertisin, in experimental model of rheumatoid arthritis. Journal of Ethnopharmacology, 235, 248-254. https:// doi.org/10.1016/j.jep.2019.02.014

Subroto, E., Widjojokusumo, E., Veriansyah, B. and Tjandrawinata, R.R. (2017). Supercritical $\mathrm{CO}_{2}$ extraction of candlenut oil: process optimization using Taguchi orthogonal array and physicochemical properties of the oil. Journal of Food Science and Technology, 54(5), 1286-1292. https:// doi.org/10.1007/s13197-017-2542-7

Vaclavik, L., Cajka, T., Hrbek, V. and Hajslova, J. (2009). Ambient mass spectrometry employing direct analysis in real time (DART) ion source for olive oil quality and authenticity assessment. Analytica Chimica Acta, 645(1-2), 56-63. https:// doi.org/10.1016/j.aca.2009.04.043

Yuliani, F., Riyanto, S. and Rohman, A. (2018). Application of FTIR spectra combined with chemometrics for analysis of candlenut oil adulteration. International Journal of Applied Pharmaceutics, 10(5), 54-59. https:// doi.org/10.22159/ijap.2018v10i5.28372 